This is an electronic reprint of the original article. This reprint may differ from the original in pagination and typographic detail.

Author(s): Kausamo, Anna; Tuononen, Heikki; Krahulic, Kelly; Roesler, Roland

Title: $\quad$ N-Heterocyclic Carbenes with Inorganic Backbones: Electronic Structures and Ligand Properties

Year: $\quad 2008$

Version:

Please cite the original version:

Kausamo, A., Tuononen, H., Krahulic, K., \& Roesler, R. (2008). N-Heterocyclic Carbenes with Inorganic Backbones: Electronic Structures and Ligand Properties. Inorganic Chemistry, 47(3), 1145-1154. https://doi.org/10.1021/ic7020929

All material supplied via JYX is protected by copyright and other intellectual property rights, and duplication or sale of all or part of any of the repository collections is not permitted, except that material may be duplicated by you for your research use or educational purposes in electronic or print form. You must obtain permission for any other use. Electronic or print copies may not be offered, whether for sale or otherwise to anyone who is not an authorised user. 


\title{
$N$-Heterocyclic Carbenes with Inorganic Backbones: Electronic Structures and Ligand Properties
}

Anna Kausamo, ${ }^{\S}$ Heikki M. Tuononen, ${ }^{{ }^{*}}$ Kelly E. Krahulic ${ }^{\dagger}$ and Roland Roesler ${ }^{\dagger}$

Departments of Chemistry, University of Jyväskylä, P.O. Box 35, FI-40014 Jyväskylä, Finland and University of Calgary, 2500 University Dr. NW, Calgary, AB, T2N 1N4, Canada.

* Author to whom correspondence should be addressed. E-mail: hetuonon@jyu.fi; Tel: +358-14260-2618; Fax: +358-14-260-2501.

$\S$ University of Jyväskylä

${ }^{\dagger}$ University of Calgary

\begin{abstract}
The electronic structures of known $\mathrm{N}$-heterocyclic carbenes (NHCs) with boron, nitrogen and phosphorus backbones are examined using quantum chemical methods and compared to the experimental results and to the computational data obtained for a classical carbon analog, imidazol2-ylidene. The $\sigma$-donor and $\pi$-acceptor abilities of the studied NHCs in selected transition metal complexes are evaluated using a variety of approaches such as energy and charge decomposition analysis, as well as calculated acidity constants and carbonyl stretching frequencies. The study shows that the introduction of selected heteroatoms into the $\mathrm{NHC}$ backbone generally leads to stronger metal-carbene bonds and therefore improves the ligand properties of these systems. The backdonation of $\pi$-electron density from the metal to the ligand is found to be strong in complexes of the studied NHCs with group 11 metals, where it constitutes up to nearly $35 \%$ of the total orbital interaction energy. The ligand properties of the aluminum analogs of some of the reported NHCs with boron backbones are also assessed.
\end{abstract}




\section{Introduction}

Classical carbenes are compounds featuring a neutral divalent carbon atom having only six electrons in its valence shell. ${ }^{1}$ Once considered to be reactive intermediates, too elusive to be isolated, ${ }^{2} N$-heterocyclic carbenes (NHCs) became bench-top reagents after 1991, when the first stable derivative, A, was reported. ${ }^{3}$ Their exceptional stability was later shown to arise from the combined $\pi$-donating and $\sigma$-withdrawing properties of nitrogen, which increase the HOMO-LUMO gap of the molecule. ${ }^{4}$ In recent years, it has been shown that the carbene backbone can be considerably modified without significant loss of stability by adjusting the ring size and/or introducing heteroatoms into the molecular framework. ${ }^{5}$ Among the more striking examples, the two $\pi$-electron cyclopropenylidene $\mathbf{B}^{6}$ and the non-planar four-membered carbene $\mathbf{C}$ with a pyramidal phosphorus backbone ${ }^{7}$ have proven to be stable at room temperature and display typical NHC behaviour. ${ }^{5 i}$ Another interesting type of modification is the replacement of one of the electronegative amino groups in NHCs by a strongly donating alkyl group, thus giving rise to cyclic (alkyl)(amino)carbenes, which display interesting chemical properties as nucleophiles. ${ }^{8}$

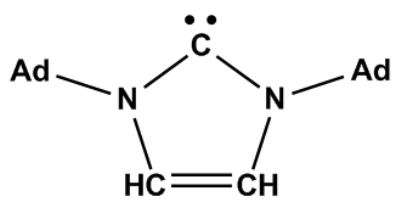

A

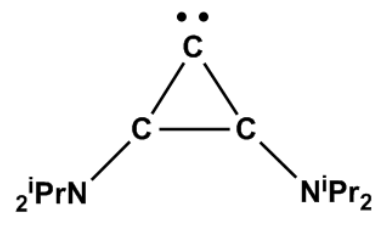

B

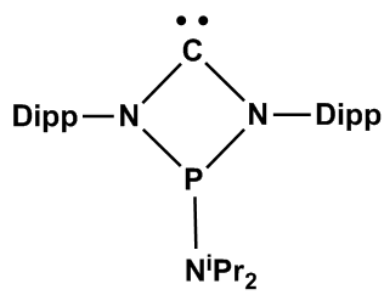

C

NHCs form stable complexes with transition metals and have found extensive applications as ancillary ligands in catalysis, ${ }^{9}$ as well as reagents and catalysts in organic chemistry. ${ }^{10}$ Therefore, it has become increasingly important to determine the effect of modifications of the carbene molecular structure on their chemical properties, especially the $\sigma$-donating ability, which largely determines their ligand behaviour. ${ }^{11}$ Though carbenes have proven to be excellent $\sigma$-donors, 
surpassing ethers, amines and phosphines in this regard, their potential as $\pi$-acceptors has only recently attracted interest. ${ }^{11,12}$

The bonding properties of NHCs have been extensively studied by employing various experimental techniques including IR-spectroscopy, ${ }^{13} \mathrm{X}$-ray diffraction, cyclic voltammetry ${ }^{14}$ and the determination of the $\mathrm{pK}_{\mathrm{a}}$ values of their conjugate acids. ${ }^{15}$ The last-mentioned method has, however, been of only minor importance as only two reports dealing with the experimental basicity of imidazol-2-ylidenes have been published. Furthermore, since geometrical parameters are not unambiguously related to electronic properties, the conclusions reached by the evaluation of bond lengths and angles can be considered somewhat speculative. For these reasons, most of the experimental investigations have been focused mainly on the analysis of the CO-stretching frequencies of the NHC-carbonyl complexes with different metals; ${ }^{13}$ a recent systematic study of a variety of $\mathrm{N}$-heterocyclic carbene-rhodium(I) dicarbonyl complexes revealed differences in their relative bonding properties and confirmed the highly $\sigma$-basic nature of the most frequently employed systems based on the imidazol-2-ylidene framework. ${ }^{13 a}$

Not only experimentalists but also theoretical chemists have found the electronic properties of carbenes intriguing. Moreover, computational work has become extremely important as its methods enable the comprehensive analysis of a great number of systems with related properties - a task that would be difficult or, in some cases, impossible using experimental methods alone. Accurate molecular geometries and vibrational frequencies as well as thermodynamic properties can be calculated theoretically by employing either density functional or wave function-based methods. Investigations on the electronic structure using charge decomposition analysis (CDA) ${ }^{16}$ and energy decomposition analysis (EDA), ${ }^{17}$ the latter within the fragment molecular orbital (FMO) approach, can be applied to obtain detailed information of individual bonding interactions within molecules. All of the above methods have previously been used to study the bonding properties of carbenes. ${ }^{12}$ The latest computational analyses of the ligand properties of imidazol-2-ylidene have collectively 
led to the conclusion that $N$-heterocyclic carbenes cannot be considered pure $\sigma$-donors but also show a moderate amount of $\pi$-bonding character in their complexes. ${ }^{11,12 \mathrm{f}}$

Although there have been detailed theoretical investigations into classical imidazole-based carbenes, ${ }^{18}$ significantly less is known about the electronic structures of the more recently reported NHCs with inorganic backbones, especially of those containing boron and phosphorus. ${ }^{19}$ Interestingly, experimental evidence shows that the ligand properties of some of these heterocyclic compounds surpass those of imidazol-2-ylidenes. ${ }^{5 f, h}$ We have now undertaken the first comprehensive DFT-based study of the electronic structures and bonding characteristics of the known NHCs with fully inorganic backbones, 1-5. ${ }^{5 f-i, 20}$ Imidazol-2-ylidene, $\mathbf{6}$, will be used as a reference point. Both free ligands and their metal complexes were investigated by applying a variety of approaches including CDA and EDA, as well as a calculation of acidity constants and IRstretching frequencies. In addition, the aromatic character of carbenes 1-3 and $\mathbf{5}$ was assessed by analysing their $\pi$-symmetric MOs and determining nucleus independent chemical shift (NICS) indices. ${ }^{21}$ The results of the current investigation are useful for the systematic development of carbenes with tailored bonding properties. In this respect, the ligand behaviour of some currently unknown aluminium analogues of $\mathbf{1}-\mathbf{3}$ was also assessed.<smiles>[R]B1N([R])[C]N([R])B([R])N1[R]</smiles><smiles>[R2]B1N([R])[C]N1[R]</smiles><smiles>[Y16]B1N([R])[C]N([R])N1[R2]</smiles>

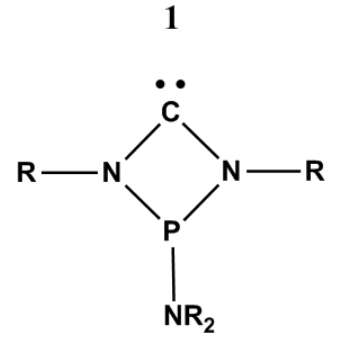

4

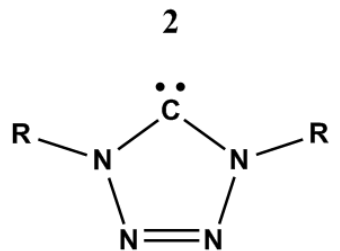

5

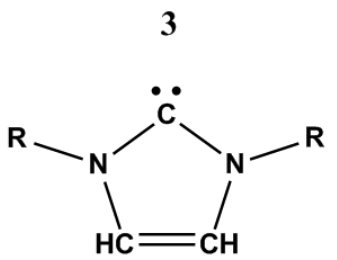

6 


\section{Computational details}

Molecular geometries were optimized with DFT using the hybrid PBE1PBE exchange-correlation functional $^{22}$ with Ahlrichs' TZVP basis sets; ${ }^{23}$ small-core $\mathrm{ECP}^{24}$ basis sets of similar valence quality were used for the transition metal nuclei. The nature of all stationary points found was assessed by performing frequency analyses. NICS values were determined for optimized structure of $\mathbf{1 , 2 , 5}$ and 6 at $1 \AA$ above the molecular plane. Only the component of the magnetic shielding tensor perpendicular to the molecular plane (zz) was used in the analysis. All calculations were carried out with the Gaussian 03 program. $^{25}$ Visualizations for Figures 1, 2 and S1 were done with the gOpenMol program. ${ }^{26}$

The bonding analyses employing the electron localization function and charge decomposition approaches were conducted with the program packages TopMod ${ }^{27}$ and CDA $2.1,{ }^{28}$ respectively. Energy decomposition analyses were performed with the ADF $2006.01 \mathrm{~b}$ program. ${ }^{29}$ The analysis followed the Morokuma-Rauk-Ziegler partition scheme ${ }^{17}$ and utilized the PBEPBE GGA functional $^{22}$ in combination with STO-type all-electron basis sets of TZP quality. ${ }^{30}$ Scalar relativistic effects were taken into account in all EDA calculations by employing the ZORA Hamiltonian. ${ }^{31}$

\section{Results and discussion}

\section{Free carbenes 1-6}

Geometries. Optimised metrical parameters of 1-6 $(\mathrm{R}=\mathrm{H})$ are listed in Supporting Information in conjunction with the available X-ray crystallographic data for their experimentally known counterparts. $^{3,5 f-1,32}$ It can be seen that generally there is a good agreement between theory and experiment, although some deviations do occur. For instance, the optimised geometries of $\mathbf{1}$ and $\mathbf{3}$, 
whose X-ray crystal structures show a small and moderate amount of ring torsion, respectively, are found to be fully planar. In contrast, carbene 2 displays the opposite trend by having a non-planar ring structure with two pyramidalised nitrogen atoms at its calculated global energy minimum.

The above differences between the calculated and crystal structures of 1-6 can be attributed to the steric bulk of the substituents. Hence, extensive calculations performed for systems 1-6 using phenyl and methyl groups were carried out in order to gain more insight into the effect of steric crowding on the molecular geometry. Upon substitution, the carbenes $\mathbf{1 , 5}$ and $\mathbf{6}$ retain a near-planar geometry, whereas the ring structure in $\mathbf{3}$ distorts from planarity due to electronic repulsion between the amino-methyl substituents. The effect of the substituents on the geometry of carbene $\mathbf{2}$ is particularly interesting: a virtually planar four-membered ring is observed for this NHC experimentally, ${ }^{5 \mathrm{~g}}$ while theoretical calculations show that, although some decrease in its ring torsion occurs, the addition of methyl and phenyl groups does not succeed in forcing the structure to a planar form. To ascertain that the planarity observed in the solid state structure of $\mathbf{2}$ is not due to lattice effects, its molecular structure was re-optimised employing the experimental substitution pattern. The calculation leads to a fully planar ring system, thereby confirming the important role of steric bulk of the substituents in determining its geometry.

Electronic structures and relative aromaticity. The molecular orbitals of $1-6(R=H)$ were analysed in their optimised geometries except for $\mathbf{2}$, whose MO analysis was conducted for a system with a planar NCNB framework. Inspection of the MOs shows that each carbene possesses a highlying $\sigma$-type HOMO, which is centred on the divalent carbon atom. Along with the fact that the orbital features suitable bonding characteristics, this confirms that the carbene lone pair in each of the ligands is readily available for coordination to metal centres.

Though initially thought to play an important role in the stabilization of NHCs, aromatic stabilisation is now known to have only a minor effect in determining the overall stability of these reagents. It is nevertheless interesting to assess the contribution of the aromatic stabilisation to the 
overall stability of the considerably more labile NHCs with inorganic backbones $\mathbf{1}-\mathbf{3}$ and $\mathbf{5}$. The $\pi$ symmetric valence MOs of NHCs 1-3 and 5-6 are shown in Figure 1; carbene $\mathbf{4}$ will be excluded from the discussion because of its non-planar geometry. The $\pi$-systems of $\mathbf{5}$ and $\mathbf{6}$, each containing a five-membered ring, are very similar and display a considerable amount of electron delocalisation, which renders the molecules subject to aromatic stabilisation. Though carbene $\mathbf{3}$ contains a fivemembered ring as well, the electron density in its $\pi_{1} \mathrm{MO}$ is concentrated mainly on the NCN moiety leaving the diboron framework virtually depleted. In addition, the presence of two amino substituents in carbene $\mathbf{3}$ means that the system contains 8 electrons in $\pi$-symmetric valence orbitals with significant contributions from the exocyclic nitrogen atoms to its $\pi_{2}$ and $\pi_{3}$ orbitals. These bonding characteristics readily explain the presence of a long BB bond in $\mathbf{3}$ and rationalize why its exocyclic $\mathrm{BN}$ bonds are shorter than the endocyclic ones.

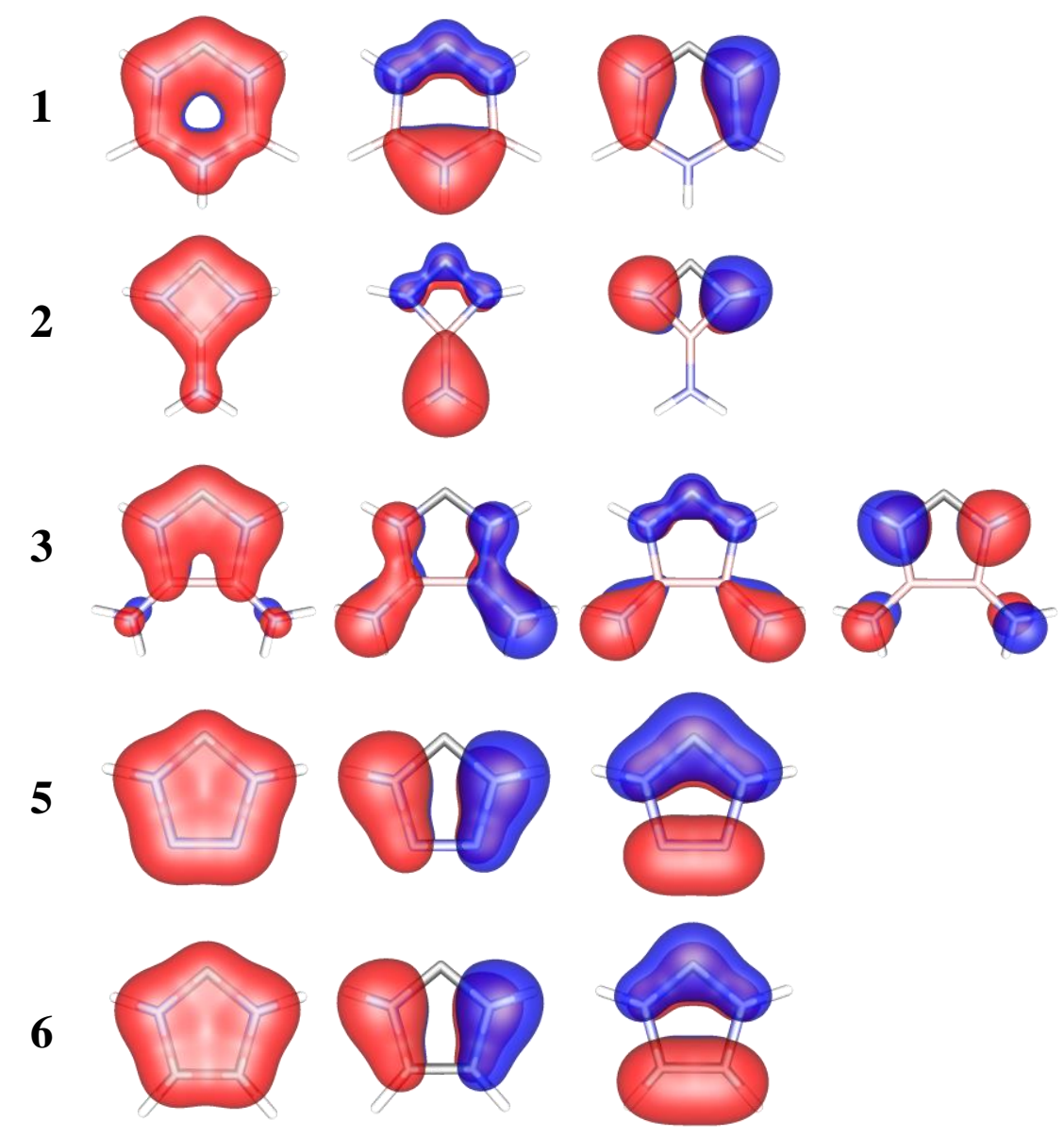

Figure 1. The $\pi$-symmetric MOs of carbenes 1-3 and 5-6 $(\mathrm{R}=\mathrm{H})$. 
Based on its metrical parameters, ring conjugation in $\mathbf{1}$ appears to be only moderate yet not entirely non-existent. The $\pi$-symmetric MOs of this six-membered ring system resemble those of $\mathbf{5}$ and $\mathbf{6}$, with significant contributions from all carbon, boron and nitrogen centres in the ring. Hence, based on MOs alone, carbene $\mathbf{1}$ can be expected to display some degree of aromaticity. The planarity of carbene $\mathbf{2}$ has been shown above to stem exclusively from steric effects. Its three $\pi$-symmetric MOs reveal that net electron delocalisation occurs in the NCN framework as well as within the exocyclic NB bond, so no ring conjugation is to be expected. Similar to carbene $\mathbf{3}$, the exocyclic NB bond is short and displays significant multiple bonding character.

One way to quantitatively assess the relative aromatic character of molecules is through the determination of their nucleus independent chemical shift (NICS) indices - a method based on the theoretical chemical shielding tensor (sign reversed) for a ghost atom residing at, or slightly above, the centre of a ring system. ${ }^{21}$ Significantly negative NICS values inside rings and cage structures indicate the presence of strong diatropic ring currents and denote aromaticity, whereas positive values, associated with paratropic ring currents, indicate opposite, antiaromatic behaviour. On MO grounds, it is reasonable to expect aromatic character for NHCs $\mathbf{5}, \mathbf{6}$ and, to a lesser extent, $\mathbf{1}$, so NICS $(1)_{z z}$ indices were calculated for these carbenes as well as for the formally four $\pi$-electron ring systems 2 and $3(\mathrm{R}=\mathrm{H}) .{ }^{33}$ For reference purposes, the NICS indices of benzene and cyclobutadiene, the two far ends of the spectrum, were also calculated.

As far as the systems under study are concerned, the magnetic features of aromaticity are well in line with the results obtained from molecular orbital analysis. Carbene $\mathbf{5}$ has a remarkably negative NICS $(1)_{z z}$ index $(-35.3 \mathrm{ppm})$ even in comparison with the corresponding value for benzene $(-29.5$ ppm) indicating significant aromatic stabilisation. Nevertheless, the carbene $\mathbf{5}$ cannot be isolated, as the stabilising contribution is not significant enough to overcome its inherent instability with respect to dissociation to dinitrogen and the corresponding carbodiimide, $\mathrm{RN}=\mathrm{C}=\mathrm{NR} .{ }^{32}$ According to its NICS index of $-7.8 \mathrm{ppm}$, the six-membered ring 1 displays some aromatic character though the 
effect is of minor importance, which is clearly seen when its NICS value is set against that of 6 (-29.3 ppm) and bearing in mind that carbene stability is, in general, attributable to aromaticity only to a small extent. ${ }^{11}$

The NICS $(1)_{\mathrm{zz}}$ indexes calculated for $\mathbf{2}$ and $\mathbf{3}$ are 11.8 and $3.1 \mathrm{ppm}$, which are positive but far less than the reference value calculated for cyclobutadiene $(55.6 \mathrm{ppm})$. Hence, as has already been discussed, carbene $\mathbf{2}$ escapes antiaromaticity by having an incomplete $\pi$-delocalization. The stabilizing effect of the amino group to the structure of $\mathbf{2}$ is best illustrated by calculating the $\operatorname{NICS}(1)_{\mathrm{zz}}$ value for a structure in which the terminal $\mathrm{NH}_{2}$ moiety has been replaced by, for example, a hydrogen atom or a methyl group. The calculations show that such hypothetical four $\pi$ electron systems would have significant antiaromatic nature with a calculated NICS index of approximately $25.0 \mathrm{ppm}$, more than twice that found for $\mathbf{2}$.

\section{Transition metal complexes of 1-6}

Geometries. Metrical parameters were optimised for various transition metal complexes of 1-6 (with $\mathrm{R}=\mathrm{H}$ ) with a varying d-electron count. The metals of each of the groups 4,6 and 11 were used as coordination centres, and the general forms of the studied complexes are as follows: $\left[\mathrm{Cl}_{5} \mathrm{M}(\mathrm{NHC})\right]^{-}$for $\mathrm{M}=\mathrm{Ti}, \mathrm{Zr}$ and $\mathrm{Hf}$ (formally $\mathrm{d}^{0}$ configuration) $7 \mathbf{a}-\mathbf{c},(\mathrm{CO})_{5} \mathrm{M}(\mathrm{NHC})$ for $\mathrm{M}=\mathrm{Cr}$,

Mo and $\mathrm{W}\left(\mathrm{d}^{6}\right) \mathbf{8 a}-\mathbf{c}$ and $\mathrm{ClM}(\mathrm{NHC})$ for $\mathrm{M}=\mathrm{Cu}, \mathrm{Ag}$ and $\mathrm{Au}\left(\mathrm{d}^{10}\right) \mathbf{9 a}-\mathbf{c}$. Experimental structural data for the studied complexes is available primarily for systems that utilize the traditional imidazol-2-ylidine based ligands. ${ }^{5 \mathrm{~h}, 32,34}$ Comparison between the theoretical data (see Supporting Information) and the existing experimental results shows a good correlation; the minor deviations being easily attributable to steric and packing effects present in the real systems. Hence, despite the significant simplifications in the ligand frameworks, the analysis of the model compounds $\mathbf{7}-\mathbf{9}$ can be expected to provide insight into how alterations in the inorganic backbone of the studied NHC ligands affect the nature of the metal-carbene interaction. 
Each of the group 11 metal complexes of NHCs 1-6 contains a linear ClMC fragment as expected for such systems. The orientation of the ligands around group 4 and 6 metal centres in complexes $\mathbf{7}$ and $\mathbf{8}$ is approximately octahedral. Comparison of the metal-carbene bond lengths in 7-9 (see Supporting Information) shows that the group 6 and 11 transition metals form the longest and shortest bonds with carbenes $\mathbf{1 / 6}$, and 2/4, respectively; the metals from group 4 exhibit a slightly different pattern and display the longest metal-NHC bonds with ligands $\mathbf{1}$ and $\mathbf{3}$. This is likely due to the effect of the carbene ring size on its capability to penetrate into the proximity of the metal centre, as the shortest bonds are always observed for NHCs with the most acute NCN bond angles. The metal-NHC bond length generally increases down a group and from right to left in a period. An interesting exception to the former is found for the group 11 complexes 9: when ordered according to increasing bond length, they display a uniform trend $\mathrm{Cu}, \mathrm{Au}$ and $\mathrm{Ag}$ i.e. the gold complexes feature metal-NHC bond lengths intermediate between those of their copper and silver analogues. Such behaviour is not unusual for compounds containing gold and is readily associated with the importance of relativistic effects for such a heavy element. ${ }^{35}$

Upon complexation, the molecular frameworks of ligands 1-6 are not significantly altered and such behaviour is typical of NHC-metal complexes. ${ }^{34}$ Some interesting results are observed for the metal complexes of carbene $\mathbf{2}$ where the ligand adopts its minimum, non-planar, geometry. Compared to the optimized structure of the free NHC, the dihedral angles of $\mathbf{2}$ are significantly diminished in both its $\mathrm{d}^{6}$ and $\mathrm{d}^{10}$ metal complexes, the calculated values ranging in between $0-4^{\circ}$ and $0-7^{\circ}$, respectively. Although a moderate decrease in dihedral angles is observed for 2 in its copper and silver compounds, the optimized geometry obtained for the gold complex stands clearly out from the rest by having a fully planar heterocyclic ring framework. This hints that the metalcarbene bond in complexes of NHC 2 with group 6 and 11 metals contains significant $\pi$ contribution with a clearly noticeable maximum when $\mathrm{M}=\mathrm{Au}$ ( $c f$. EDA results below). 
Molecular orbital analysis. As discussed above, the HOMOs of 1-6 have both proper symmetry and energetic accessibility to allow these NHCs to act as excellent $\sigma$-donors. However, there are also $\pi$-type MOs in NHCs 1-6 that fulfil the requirements for interacting with the orbitals of the metal fragments in complexes 7-9. While the occupied $\pi$-orbitals depicted in Figure 1 do not alone result in net bonding contributions with the filled metal orbitals, they are able to mix with their unoccupied counterparts, thus resulting in overall stabilizing $\pi$-interactions.

The nature of the metal-NHC bond in 7-9 was analyzed using the fragment molecular orbital method, which reveals that in all systems there are both $\sigma$-bonding and $\pi$-backbonding interactions. ${ }^{36}$ The two most important bonding MOs of the complex 9c containing the NHC $6(\mathrm{R}=$ H) are depicted in Figure 2. As shown, the $\sigma$-bonding results mainly from the interaction of the filled HOMO of the NHC fragment with the $3 \mathrm{~d}_{\mathrm{z}^{2}}+6 \mathrm{~s}$ hybrid orbital of the central metal Au (orbital $\sigma_{\mathrm{B}}$ ), whereas the $\pi$-interaction is due to the overlap of the partially empty ligand $\pi$-orbital with the filled $\pi$-symmetric $\mathrm{p}(\mathrm{Cl})+\mathrm{d}(\mathrm{Au})$ hybrid orbital on the metal fragment (orbital $\pi_{\mathrm{B}}$ ).

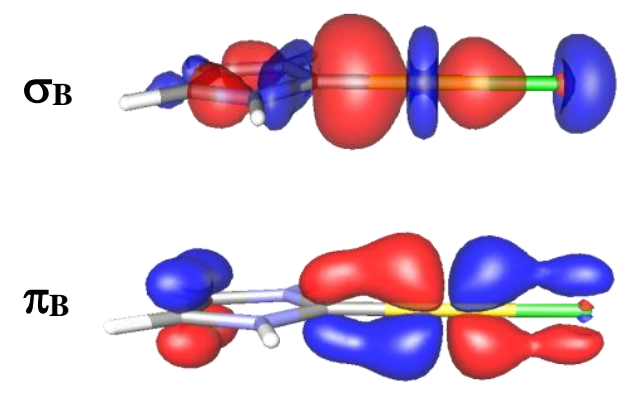

Figure 2. The important bonding MOs in complex 9c containing the NHC ligand $6(\mathrm{R}=\mathrm{H})$.

Energy decomposition analysis. The orbital characteristics and energetic properties of metal-NHC bonds in 7-9 were examined by employing energy decomposition analysis. ${ }^{17}$ Recently, the same method has been used to analyse various transition metal complexes of imidazol-2-ylidene and the discussion below will closely follow the previous work. ${ }^{12}$ 
The energy associated with the bond formation between molecular fragments, both possessing the optimised geometries of the final complex, will be referred to as the total bonding energy $\Delta E_{\text {tot. }}{ }^{37}$ According to EDA, $\Delta E_{\text {tot }}$ can be decomposed into the steric and orbital interaction parts, $\Delta E^{0}$ and $\Delta E_{\text {int }}$, respectively: $\Delta E_{\text {tot }}=\Delta E^{0}+\Delta E_{\text {int. }}$ The steric interaction between the metal and carbene fragments consists of purely electrostatic interaction $\Delta E_{\text {elstat }}$ and a term $\Delta E^{\text {Pauli }}$ corresponding to the Pauli repulsion (i.e. two orbital, three or four electron interactions) between occupied orbitals on both fragments. The former has a stabilising contribution to the bond formation while the latter tends to destabilise the bond, and their relative importance determines the effect of $\Delta E^{0}$ on the total interaction energy between the fragments.

The total orbital interaction energy $\Delta E_{\text {int }}$ has an instructive interpretation as a sum of contributions from the various irreducible representations of the molecular point group. Therefore, by assessing the symmetry of the system, the $\sigma$ - and $\pi$-characteristics of the interaction between its fragments are easily determined. The latter is conveniently described as consisting of contributions from $\pi$-backdonation (metal to ligand) and $\pi$-donation (ligand to metal), the amount of which are found out by performing constrained space orbital variation (CSOV) calculations. ${ }^{38}$ In such a procedure, the energy decomposition analysis is carried out as usual but the unoccupied $\pi$-orbitals from the carbene and metal fragments are successively removed from the calculations in order to assess the amount of $\pi$-donation and backdonation, respectively.

Complexes 7-9 with NHCs 1-6 $(\mathrm{R}=\mathrm{H})$ were subjected to EDA analysis and the numeric results are given in the Supporting Information. A planar geometry was assumed for carbene $\mathbf{2}$ in its complexes as this is in agreement with the experimental data and it allows factorization of the orbital interaction term to different $\sigma$ - and $\pi$-contributions. In line with the previous results obtained for imidazol-2-ylidene, ${ }^{12 \mathrm{e}}$ the major contribution to carbene-metal bonding comes from the orbital interaction term but the observed trends are unambiguously paralleled neither in steric nor in orbital interaction energies. However, closer inspection of the origin of $\Delta E_{\text {int }}$ proved to be instructive in 
this respect (see below). For group 4 complexes, the Pauli repulsion outweighs the attractive electrostatic interaction and the overall effect of steric interaction is destabilizing, thus leading to more positive total bonding energies. The situation is reversed in group 11 complexes, whereas group 6 compounds display ambivalent behaviour: the $\Delta E^{0}$ term is positive for chromium, almost vanishing for molybdenium and slightly negative for all wolfram complexes.

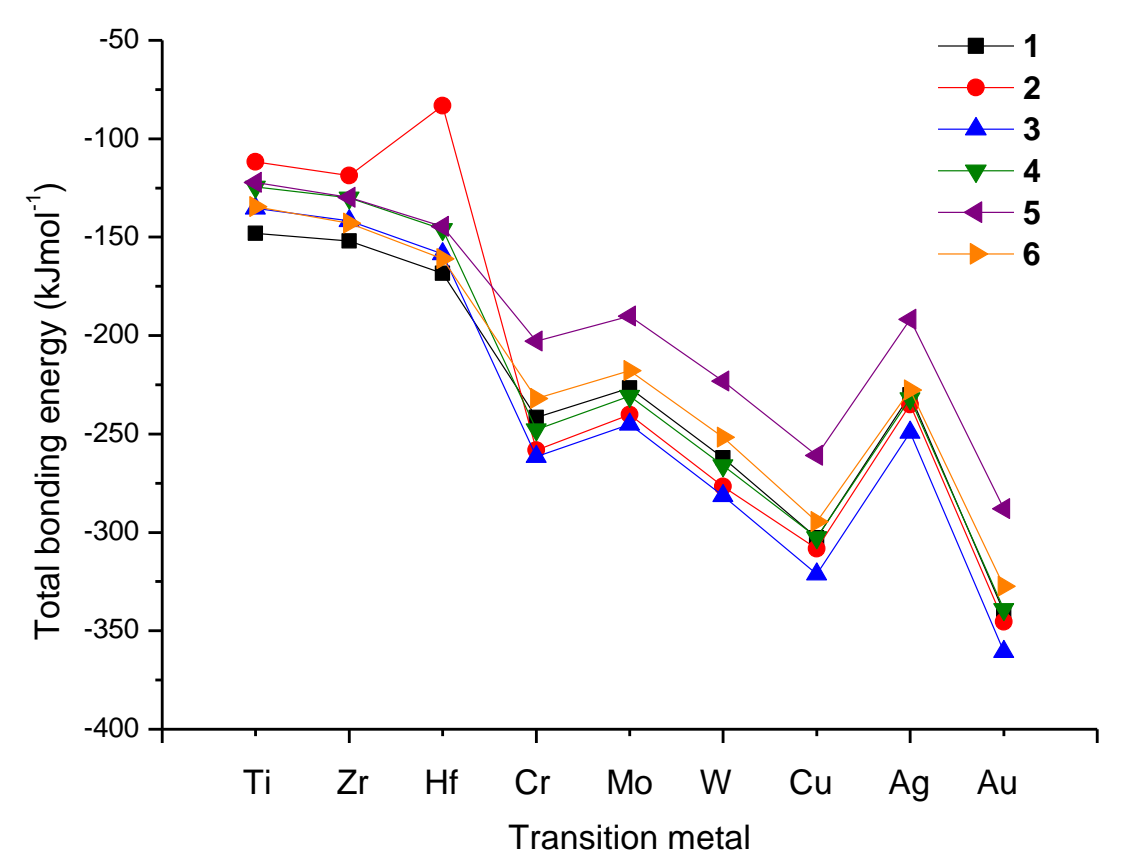

Figure 3. Total bonding energies of complexes 7-9 with NHCs 1-6.

The total bonding energies $\Delta E_{\text {tot }}$ calculated for 7-9 are presented graphically in Figure 3. In general, the weakest bonds with a $\Delta E_{\text {tot }}$ at around $-125 \mathrm{~kJ} \mathrm{~mol}^{-1}$ are observed for group 4 complexes, while group 11 metals, especially Au, display the most negative total bonding energies. A particularly weak Hf-NHC bond in the complex 7c of NHC 2 stems from the relatively high Pauli repulsion energy of $749 \mathrm{~kJ} \mathrm{~mol}^{-1}$, which in turn results in an overall destabilising steric interaction term. The metal-ligand bond strength increases down a group for $\mathrm{d}^{0}$ complexes while for $\mathrm{d}^{6}$ and $\mathrm{d}^{10}$ compounds the middle member of each group lies the highest in energy. Among group 6 and 10 complexes, the best fragment orbital energy correspondence between the carbenes and respective 
metal fragments is found for the $\mathrm{Cr}$ and $\mathrm{Cu}$ systems while only relatively poor energy matching occurs for the analogous Mo and Ag complexes. This readily explains the observed dependence of the strength of a metal-NHC interaction on the atomic number for systems with a given formal delectron count.

Of all the systems studied, the carbenes $\mathbf{3}$ and $\mathbf{5}$ form the strongest and weakest bonds with a given metal, respectively. The only exceptions are the $\mathrm{d}^{0}$ metal complexes of $\mathbf{2}$ and $\mathbf{1}$. For the former three systems, the carbene-metal bond is weaker than for the corresponding compounds of ligand 5, whereas the total bonding energies for the latter systems are the most negative with respect to other group 4 metal complexes. The tendency of ligand 5 to form relatively weak bonds parallels the above discussion concerning the properties of its frontier molecular orbitals. The trends in $\Delta E_{\mathrm{tot}}$ also show that there exists no correlation between bond length and the calculated total bonding energy.

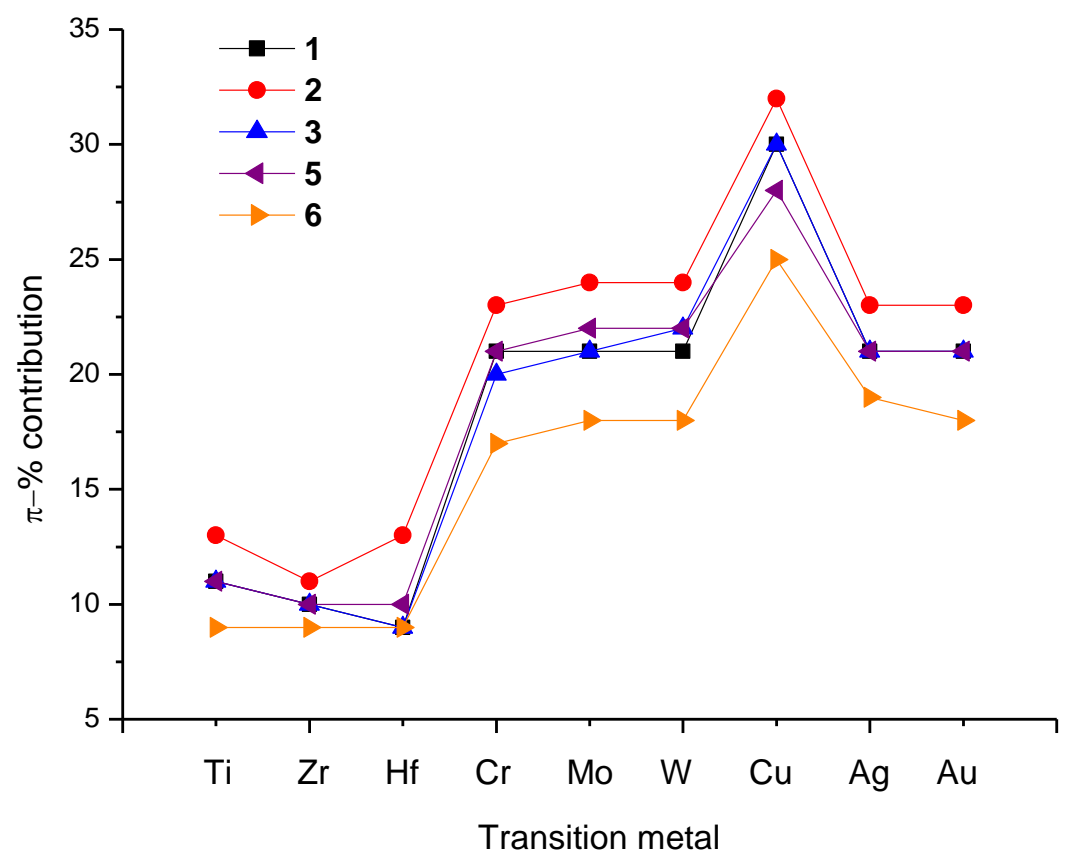

Figure 4. $\pi$-Contribution to the $\Delta E_{\text {int }}$ of complexes 7-9 of NHCs 1-3, 5 and $\mathbf{6}$. 
Along with the $\sigma$-donation, there also exists a moderate amount of orbital interaction energy corresponding to $\pi$-interactions, the relative importance of which is depicted in Figure 4 for systems 7-9 with NHC ligands 1-3,5 and 6; carbene 4 was excluded because of its lack of planarity that prevents the decomposition of the orbital interaction energy term. As displayed in the graph, $\pi$ interactions are the least important for group 4 complexes (at around $10 \%$ of $\Delta E_{\text {int }}$ ) and their significance increases with increasing d-electron count. The relative amount of $\pi$-interaction reaches its maximum in $\mathrm{Cu}-\mathrm{NHC}$ complexes in which it constitutes $25-32 \%$ of the orbital term. When absolute values of different components in $\Delta E_{\text {tot }}$ are set against the total bonding energies, the $\pi$-interactions appear to be the most important in the gold systems. Unsurprisingly, the strongest $\pi$ contributions are observed in the Au complex of the four-membered NHC ligand 2 . The above observations are readily attributable to indirect relativistic effects, which result in the expansion of the gold d orbitals, ${ }^{35}$ thus enabling enhanced $\pi$-interactions.

Figure 4 also shows that the relative importance of $\pi$-interactions is largely independent of the type of NHC used. The smallest relative (and also absolute) $\pi$-contributions are observed for the more traditional carbene 6, whereas the values for most NHCs with inorganic backbones are a few percent higher. The values calculated for the complexes of carbene $\mathbf{2}$ are the highest, another few percent higher than for the other carbenes with inorganic backbones. To analyse the nature of the metal-NHC $\pi$-interactions one step further, CSOV calculations were performed for $\mathrm{d}^{0}, \mathrm{~d}^{6}$ and $\mathrm{d}^{10}$ complexes of $\mathbf{1 - 3}, \mathbf{5}$ and $\mathbf{6}$. It was determined that backdonation from metal to ligand plays a major role in $\pi$-interactions, its percentage increasing with increasing d-electron count - from around 70 $\%\left(\mathrm{~d}^{0}\right)$ to close to $95 \%\left(\mathrm{~d}^{10}\right)$. Hence, the $\pi$-contributions shown in Figure 4 are of almost pure backdonation type and contain no significant contributions from ligand to metal type interactions i.e. the carbenes 1-6 behave as $\pi$-acceptors. In addition, the analysis shows that the nature of $\pi$ contribution is much more dependent on the metal fragment than on the identity of the carbene 
ligand as only small variations between systems 1-6 were observed. These conclusions are not unlike those obtained for complexes of imidazol-2-ylidene. ${ }^{12 \mathrm{e}}$ As a whole, the inspection of individual components of $\Delta E_{\text {int }}$ to the bonding generalises the previous result: ${ }^{11,12 a-e}$ carbenes whether more traditional or with inorganic backbones - cannot, by far, be considered pure $\sigma$ donors.

Charge decomposition analysis. The nature of donor-acceptor interactions in transition metal complexes can be investigated using the charge decomposition scheme ${ }^{16}$ in which the MOs of the complex are expressed in terms of the orbitals of the pre-chosen fragments, typically those of the ligand(s) and the metal fragment. The orbital contributions can be divided into three parts: (i) the mixing of the occupied MOs of the ligand and the unoccupied MOs of the metal fragment $(\sigma-$ donation); (ii) the mixing of the unoccupied MOs of the ligand and the occupied MOs of the metal fragment ( $\pi$-backdonation); and (iii) the mixing of the occupied MOs of the ligand and the occupied MOs of the metal fragment (repulsive polarization). The CDA method has been particularly helpful in elucidating the binding in donor-acceptor complexes of transition metals with main group elements, ${ }^{39}$ and it has also been used to study the bonding in group 11 metal complexes of $N$ heterocyclic carbenes. $^{12 \mathrm{f}}$

In the current study, the primary aim was to apply CDA as an alternative method to analyse metal-NHC interactions in transition metal complexes 7-9 and to compare the results to the data from energy decomposition analyses. This presented a problem as it soon became apparent that the numeric values given by the CDA procedure are extremely sensitive to the nature of the chosen basis sets. For instance, when the ECP basis set is used for copper, the calculated donation/backdonation ratio for the complex 9a with the NHC ligand $\mathbf{1}(\mathrm{R}=\mathrm{H})$ is 8.69 . This value is in reasonable agreement with the previous results published for this system, $6.64,{ }^{12 \mathrm{f}}$ and indicates almost negligible contribution from metal to ligand backdonation. However, if all-electron TZVP quality basis sets are used for all elements, the donation/backdonation ratio for the copper complex 
is significantly smaller, only 1.53 , which leads to the opposite conclusion that NHCs are equally good $\pi$-acceptors as typical Fischer carbenes.

It is tempting to assign the observed basis set dependence of the calculated donation/backdonation ratio to the different treatment of relativity in the two calculations. However, it is highly unlikely that relativistic effects would play such a huge role for copper, a fourth period nucleus. Moreover, if relativity would indeed be the key factor, the observed trend should actually be reversed: relativity leads to a contraction of the $s$ and $p$ orbitals, and to more diffuse $d$ and $f$ orbitals, which would be expected to result in smaller donation/backdonation ratios for calculations utilizing pseudopotential basis sets with built-in - albeit indirect - treatment of relativistic effects. We also note that the CDA results obtained with the all-electron TZVP basis sets are consistent with the other results published herein and also with the data reported in previous publications discussing the bonding in related NHC-metal complexes. ${ }^{12 a-e}$ In conclusion, CDA does not appear to be a reliable method for the assessment of donation and backdonation in the compounds discussed herein.

\section{Relative $\sigma$-donor abilities of 1-6}

Considering systems 1-6, the qualitative frontier MO theory predicts that molecules that have highenergy electron donating orbitals will be good electron donors and vice versa. However, it must be pointed out that electrostatic effects and the relative orbital energy differences between the ligand and the metal fragment are both very important factors in determining the nature of the metal-ligand bond. Nevertheless, some indication of the relative $\sigma$-donor strength of $\mathbf{1}-\mathbf{6}$ can be obtained by comparing their calculated HOMO energies. ${ }^{40}$ The results show that for most of the studied NHCs, these energies are very close to the level calculated for imidazol-2-ylidene. However, the HOMOs in carbenes $\mathbf{3}(-5.42 \mathrm{eV})$ and $\mathbf{5}(-7.48 \mathrm{eV})$ are significantly higher and lower in energy, respectively, when set against the parent NHC system $6(-6.18 \mathrm{eV})$. This result is in good agreement with the 
published experimental data and indicates exceptional ligand behaviour for the NHC with a diboron backbone, 3. $^{5 \mathrm{~h}, 32}$

Carbonyl stretching frequencies. An indirect method to analyse the relative $\sigma$-donor abilities of ligands is to measure the $\mathrm{CO}$-stretching frequencies of their carbonyl complexes. The lower the $v(\mathrm{CO})$ corresponding to the $\mathrm{CO}$ group in trans position to the investigated ligand, the stronger $\sigma$ donor this ligand generally is. However, the carbonyl stretching frequencies are dependent not only on the $\sigma$-bonding but also on the strength of the $\pi$-interaction within the metal-NHC bond: the better the $\pi$-acceptor ability of a carbene, the smaller the observed decrease in $v(\mathrm{CO})$ is, as "excess" electron density from the metal can be transferred back to the NHC ligand. In order to have meaningful comparisons, the ligands used as well as the substitution pattern of the studied systems must be as similar as possible, as the comparison is made between values that differ by only a few wavenumbers. This method has been widely used in the experimental determination of $\sigma$-donor characteristics of $\mathrm{N}$-heterocyclic carbenes ${ }^{13}$ including, as a part of an extensive comparative study, ${ }^{13 a}$ some systems with partially or fully inorganic backbones.

Table 1. Calculated CO-stretching vibrations in transition metal complexes of $\mathbf{1 - 6}\left(\mathrm{cm}^{-1}\right){ }^{a}$

\begin{tabular}{|c|c|c|c|c|}
\hline & \multicolumn{3}{|c|}{$(\mathrm{CO})_{5} \mathrm{M}(\mathrm{NHC})$} & \multirow{2}{*}{$\frac{(\mathrm{CO})_{2}(\mathrm{Cl}) \mathrm{M}(\mathrm{NHC})}{\mathrm{Rh}}$} \\
\hline & $\mathrm{Cr}$ & Mo & W & \\
\hline 1 & 2072 & 2073 & 2067 & 2101 \\
\hline 2 & 2076 & 2076 & 2070 & 2108 \\
\hline 3 & 2067 & 2067 & 2062 & 2097 \\
\hline 4 & 2072 & 2072 & 2066 & 2109 \\
\hline 5 & 2079 & 2080 & 2074 & 2117 \\
\hline 6 & 2064 & 2064 & 2059 & 2101 \\
\hline
\end{tabular}

As the calculated group 6 complexes of 1-6 contain carbonyl ligands, the $v(\mathrm{CO})$ frequency based analysis of their relative $\sigma$-donor strengths is easily conducted. The symmetric $\mathrm{CO}$ stretching frequencies for $(\mathrm{CO})_{2}(\mathrm{X}) \mathrm{Rh}(\mathrm{NHC})(\mathrm{X}=$ halogen $)$ complexes were calculated in addition to those 
for 8a-c since they are particularly useful in a comparative sense having been widely used in the experimental analyses. The results of the calculations are presented in Table 1.

The trends in carbonyl stretching frequencies of complexes $\mathbf{8 a}-\mathbf{c}$ with NHC ligands $\mathbf{1}-\mathbf{5}$ are independent of the transition metal used and in reasonable agreement with the MO and EDA analysis based trends in carbene $\sigma$-donor strengths (see above). Interestingly, in all the complexes, $\mathbf{8}$, it is the carbene $\mathbf{6}$ that shows the lowest $v(\mathrm{CO})$ values in the series, contradicting experimental observations. ${ }^{5 \mathrm{~h}, 13}$ This deviation probably arises from computational uncertainties as well as the effect of using fully hydrogen substituted systems in the calculations; it is reasonable to expect that the addition of organic substituents to structures 1-4 can result in small changes in the calculated frequencies. As a matter of fact, in the calculated $v(\mathrm{CO})$ values of $\mathbf{3}$ with methyl substituents on the exocyclic nitrogen atoms, the agreement with the experimental trend is restored as these frequencies become the lowest of group 6 complexes of 1-6. In the calculated rhodium complexes, however, the expected trend is reproduced even in the hydrogen-substituted systems. As a whole, the results above suggest that this method, especially as conducted computationally, can give only a direction for $\sigma$-donation characteristics and is valid only for the prediction of trends. Even when applied for such purpose it can be deceptive unless systems close (or preferably identical) to the experimental ones are used. To conclude, the trends in calculated $v(\mathrm{CO})$ stretching frequencies show that carbenes $\mathbf{1}$ and $\mathbf{3}$ are equally good, or better, electron donors as imidazol-2-ylidine, whereas the carbene 5 with a nitrogen-based backbone is undoubtedly the worst in the series.

Acidity constants. In addition to the analyses above, the relative $\sigma$-donating properties of NHCs 1-6 $(\mathrm{R}=\mathrm{H})$ can be assessed by determining their basicity in solution. This is most conveniently done by calculating the acidity constants ( $\mathrm{p} K_{\mathrm{a}}$ values) for their conjugate acids $\mathbf{1 H}^{+}-\mathbf{6} \mathbf{H}^{+}{ }^{41}$ However, much to the computational chemists' dismay, the quantum chemical determination of absolute $\mathrm{p} K_{\mathrm{a}}$ values is a highly demanding task, requiring the use of methods that give very accurate energies: an error of only $5 \mathrm{~kJ} \mathrm{~mol}^{-1}$ in calculating the free energy of a deprotonation in solution 
results in an error a little shy of one $\mathrm{p} K_{\mathrm{a}}$ unit. Fortunately, the acidity constants can also be determined in a relative manner by using an experimentally known $\mathrm{p} K_{\mathrm{a}}$ value of another acid as a reference standard. Recently, the $\mathrm{p} K_{\mathrm{a}}$ values of 12 nucleophilic carbenes based on the imidazole and thiazole frameworks were determined using computational methods. ${ }^{41}$ The results showed that, when ranked according to basicity, the carbenes follow an identical pattern independent of the solvent employed and whether the acidity constants were calculated in a relative or absolute manner.

The acidity constants of $\mathbf{1} \mathbf{H}^{+}-\mathbf{6} \mathbf{H}^{+}(\mathrm{R}=\mathrm{H})$ were calculated in a dimethyl sulfoxide solution using pyrazole as a reference standard $\left(\mathrm{p} K_{\mathrm{a}}=19.8\right)$. Both geometry optimizations and the calculations of the free energies of solvation were conducted using the polarized continuum solvent model $(\mathrm{CPCM})^{42}$ at the PBE1PBE/TZVP level of theory. The calculations give the parent imidazol2-ylidine $6 \mathbf{H}^{+}$a $\mathrm{p} K_{\mathrm{a}}$ of 21.8 which is very close to the values reported for its $N$-Me and $N$ - ${ }^{\mathrm{t}} \mathrm{Bu}$ substituted derivatives, $21.1^{41}$ and $22.7,{ }^{15 b, 41}$ respectively. The highest $\mathrm{p} K_{\mathrm{a}}$ value 26.5 was calculated for $\mathbf{3} \mathbf{H}^{+}$, which again indicates a highly basic nature for the diboron backboned ligand $\mathbf{3}$; the $\mathrm{p} K_{\mathrm{a}}$ value for the protonated six-membered carbene $\mathbf{1 H}^{+}$is somewhat smaller, 23.8. The calculated acidity constants for $\mathbf{2} \mathbf{H}^{+}, \mathbf{4} \mathbf{H}^{+}$and $\mathbf{5} \mathbf{H}^{+}$are $20.1,20.5$ and 7.3 , respectively. Hence, while the four-membered carbenes $\mathbf{2}$ and $\mathbf{4}$ are both almost equally basic as the parent NHC, the tetrazole carbene $\mathbf{5}$ is the least basic species in the series by a clear margin.

It needs to be pointed out here that the above calculations have completely neglected the effect of different substituents to the $\mathrm{p} K_{\mathrm{a}}$ values as the analysis has been performed only for the $\mathrm{R}=\mathrm{H}$ series. In general, the effect of $N$-substituents to the acidity constants of imidazol-2-ylidine seems to be small when simple alkyl chains such as $\mathrm{Me},{ }^{\mathrm{i}} \mathrm{Pr}$ and ${ }^{\mathrm{t}} \mathrm{Bu}$ are used, but it becomes more significant when aromatic ring systems are employed. ${ }^{41}$ It can be estimated that most of the studied systems 1-5 would display significantly reduced $\mathrm{p} K_{\mathrm{a}}$ values if experimental structures with $N$-Dipp substituents were used in the analysis. To shed more light on this issue, the $\mathrm{p} K_{\mathrm{a}}$ values of protonated 
carbene $\mathbf{3} \mathbf{H}^{+}$were calculated using methyl and phenyl substituents. The $N$-Ph derivative of $\mathbf{3}$ has a $\mathrm{p} K_{\mathrm{a}}$ value of 22.9 which is clearly less than what was calculated for the $\mathrm{R}=\mathrm{H}$ structure but still much higher than the value obtained for the analogously substituted imidazole framework (16.1). The acidity constant for $3 \mathbf{H}^{+} \mathrm{R}=\mathrm{Me}$ is $\mathbf{2 4 . 4}$, a value that does not disagree with the general trend observed for the imidazole-based systems. ${ }^{41}$

Taken as a whole, the calculated acidity constants support the results from EDA, MO and carbonyl stretching frequency calculations, and lend further support to the good ligand properties of NHC 3. However, as these methods probe $\sigma$-donation, which is not a measurable quantity in itself, from slightly different perspectives, some variations in their results is natural. Moreover, the bonding ability of a ligand is dependent not only on its properties but also on the metal to which it binds to, and is susceptible to the effect of the other ligands on the electronic structure of the complex. Hence, it is impossible to put the series of systems examined here in any definite order with respect to $\sigma$-donation. As a general remark, we note that the consideration of carbenes 1-6 leads to the conclusion that all systems 1-4 with an inorganic backbone display bonding characteristics comparable or better to the more traditional NHCs and that the carbene $\mathbf{3}$ with a diboron backbone stands out from the rest in the majority of the analyses conducted.

\footnotetext{
Aluminium analogues of 1-3

All of the conducted analyses point towards the fact that the NHCs containing boron atoms as a part of their backbones show particularly promising ligand properties. It is, therefore, reasonable to ask what happens to these characteristics if the boron atoms in $\mathbf{1 - 3}$ are substituted for e.g. aluminium. In order to gain predictions about the matter, theoretical calculations were performed for hitherto unknown aluminium analogues 10-12 of $\mathbf{1}-\mathbf{3}$ and their group 11 complexes $9 \mathbf{a}-\mathbf{c}$.
} 
<smiles>[R][C]1N([R])[C]N([R])[Si]([R])N1[R]</smiles>

10

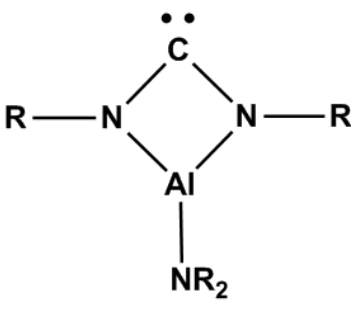

11

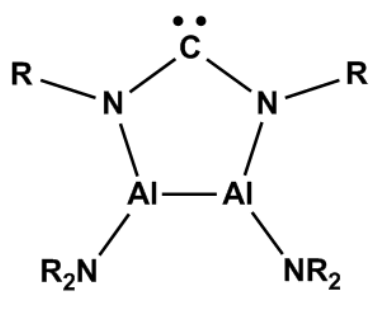

12

The structural trends observed for 1-3 are reproduced in their aluminium analogues with the exception of $\mathbf{1 1}$ which displays a planar geometry even when hydrogen substituents are used. According to the MO structure of the system, the planarity does not originate from $\pi$-electron delocalisation as all $\pi$-orbitals show complete depletion of electron density from the endocyclic AlN bond. In general, the change of boron to aluminium leads to significant lowering of the virtual $\pi$-orbitals, yet the properties of the $\sigma$-donating HOMOs in 10-12 are not altered to a great extent.

The EDA analysis employed for the metal complexes of 10-12 shows no remarkable differences compared to the boron systems, which is mainly due to the cancellation between two electronic effects. First, there is a general increase in the $\sigma$-interaction energy between the ligand and transition metal on going from boron to aluminium NHCs. Second, the $\pi$-contributions to the metal-ligand bonding seem to be diminished for 10-12. The combined effect of these two changes is a virtually unaltered total orbital interaction term, which leaves the bonding energies practically unaffected. An exception for this is carbene $\mathbf{1 1}$ that displays approximately $20 \mathrm{~kJ} \mathrm{~mol}^{-1}$ increased $\Delta E_{\text {tot }}$ values for all its group 11 complexes as a result of electronic destabilisation due to increased steric interactions. The origin of this effect is in the significant increase (around $10^{\circ}$ ) of the NCN bond angle, which accompanies the change of boron to aluminium. Even though the $\pi$-orbitals in 10-12 are lowered in energy with respect to the boron analogues, their localisation on the group 13 
centres subdues the contribution from carbon $\mathrm{p}$ orbitals, which, in turn, suppresses $\pi$-backbonding interactions in the metal complexes.

\section{Conclusions}

In this computational study, the electronic structures and ligand properties of various $N$-heterocyclic carbenes with inorganic backbones were examined. In general, the results show that the increased carbene-transition metal bond strength that generally accompanies the introduction of selected heteroatoms into the ligand skeleton should enable application-oriented tuning of the ligand properties of NHCs.

The analysis of molecular structures and bonding in 1-6 confirms that ring conjugation affects the electronic structure of the six-membered heterocycle $\mathbf{1}$ only to a modest amount. The planarity of carbene $\mathbf{2}$ was shown to stem exclusively from steric effects; this system also escapes destabilizing antiaromaticity by having an incomplete $\pi$-delocalization due to the presence of an exocyclic amino group. The analysis also confirms the non-aromatic nature of the diboron system $\mathbf{3}$ and significant aromatic stabilization present in the tetrazole carbene $\mathbf{5}$.

According to the various theoretical methods employed, the NHC with a diboron backbone $\mathbf{3}$ stands out from the rest as far as ligand capabilities are concerned, and the six and four-membered ring systems $\mathbf{1}$ and $\mathbf{2}$, respectively, bind relatively strongly to transition metal centres as well. Irrespective of the theoretical method applied, the weakest bonding interactions were found for the tetrazole carbene 5, in agreement to its experimentally observed behaviour. Although the carbene 4 with a phosphorus backbone is less basic and does not bind to metals as strongly as the boron-based systems, it is, nonetheless, found to be a better ligand than imidazol-2-ylidene in complexes with high formal d-electron count.

Inspection of the nature of metal-NHC bonds in complexes 7-9 revealed that $\pi$-interaction has a moderate contribution in all systems studied, ranging from $c a$. $10 \%$ to almost $35 \%$ of the total 
orbital interaction energy, the maximum values being reached by group 11 complexes. This is well in line with the previous works based on the study of imidazol-2-ylidene complexes and shows that $\pi$-interactions form an important feature in the electronic structures of all $N$-heterocyclic carbene complexes. The $\pi$-interactions are dominated by the backbonding contribution (from metal to ligand) whose significance increases with increasing d-electron count in all complexes 7-9, reaching values greater than $90 \%$ of total $\pi$-interactions.

The analyses conducted for aluminium analogues of 1-3 indicated that the identity of the group 13 element has little effect on the general ligand properties of NHCs. Hence, systems $\mathbf{1 0}-\mathbf{1 2}$ could represent interesting targets for future synthetic attempts.

\section{Acknowledgement}

We thank the Academy of Finland, the University of Jyväskylä, the Natural Science and Engineering Research Council (NSERC) of Canada, and the University of Calgary for their generous financial support.

\section{References and notes}

${ }^{1}$ (a) Bourissou, D.; Guerret, O.; Gabbaï, F. P.; Bertrand, G. Chem. Rev. 2000, 100, 39. (b) Bertrand, G. (Ed.) Carbene Chemistry, Marcel Dekker: New York, 2002. (c) Alder, R. W.; Blake, M. E.; Chaker, L.; Harvey, J. N.; Paolini, F.; Schütz, J. Angew. Chem. Int. Ed. 2004, 43, 5896. (d) Nair, V.; Bindu, S.; Sreekumar, V. Angew. Chem. Int. Ed. 2004, 43, 5130. (e) Enders, D.; Balensiefer, T. Acc. Chem. Res. 2004, 37, 534. (f) Kühl, O. Chem. Soc. Rev. 2007, $36,592$.

2 (a) Arduengo, A. J. III Acc. Chem. Res. 1999, 32, 913. (b) Arduengo, A. J. III; Krafczyk, R. Chem. Unserer Zeit 1998, 32,6 .

${ }^{3}$ Arduengo, A. J. III; Harlow, R. L.; Kline M. J. Am. Chem. Soc. 1991, 113, 361.

${ }^{4}$ (a) Heinemann, T. M.; Apeloig, Y.; Schwarz, H.; J. Am. Chem. Soc. 1996, 118, 2023. (b) Boehme, C.; Frenking, G. J. Am. Chem. Soc. 1996, 118, 2039.

${ }^{5}$ (a) Bazinet, P.; Yap, G. P. A.; Richeson, D. S. J. Am. Chem. Soc. 2003, 125, 13314. (b) Guillen, F.; Winn, C. L.; Alexakis, A. Tetrahedron: Asymmetry 2001, 12, 2083. (c) Alder, R.W.; Blake, M. E.; Bortolotti, C.; Bufali, S.; Butts, C. P.; Linehan, E.; Oliva, J. M.; Orpen, A. G.; Quayle, M. J. Chem. Commun. 1999, 241. (d) Scarborough, C. C.; Grady, M. J. W.; Guzei, I. A.; Gandhi, B. A. Stahl, S. S. Angew. Chem., Int. Ed. 2005, 44, 5269. (e) Scarborough, C. C.; Popp, B. V.; Guzei, I. A.; Stahl, S. S. J. Organomet. Chem. 2005, 690, 6143. (f) Präsang, C.; Donnadieu, B.; Bertrand, G. J. 
Am. Chem. Soc. 2005, 127, 10182. (g) Ishida, Y.; Donnadieu, B.; Bertrand, G. Proc. Natl. Acad. Sci. $2006,103,13585$.

(h) Krahulic, K. E.; Enright, G. D.; Parvez, M.; Roesler, R. J. Am. Chem. Soc. 2005, 127, 4142. (i) Despagnet-Ayoub, E.; Grubbs, R. H. J. Am. Chem. Soc. 2004, 126, 10198.

${ }^{6}$ Lavallo, V.; Canac Y.; Donnadieu, B.; Schoeller, W.W.; Bertrand, G. Science 2006, 312, 722.

${ }^{7}$ Despagnet-Ayoub, E.; Grubbs, R. H. Organometallics 2005, 24, 338.

${ }^{8}$ (a) Lavallo, V.; Canac, Y.; Präsang, C.; Donnadieu, B.; Bertrand, G. Angew. Chem., Int. Ed. 2005, 44, 5705. (b) Frey, G. D.; Lavallo, V.; Donnadieu, B.; Schoeller, W. W.; Bertrand, G. Science, 2007, 316, 439.

${ }^{9}$ (a) Jafarpour, L.; Nolan, S. P. J. Organomet. Chem. 2001, 617 - 618, 17. (b) Enders, D.; Gielen, H. J. Organomet. Chem. 2001, 617 - 618, 70. (c) Herrmann, W. A. Angew. Chem., Int. Ed. 2002, 41, 1290. (d) Hillier, A. C.; Grasa, G. A.; Viciu, M. S.; Lee, H. M.; Yang, C.; Nolan, S. P. J. Organomet. Chem. 2002, 653, 69. (e) Perry, M. C.; Burgess, K. Tetrahedron: Asymmetry 2003, 14, 951. (f) Peris, E.; Crabtree, R. H. Coord. Chem. Rev. 2004, 248, 2239. (g) Crudden, C. M.; Allen, D. P. Coord. Chem. Rev. 2004, 248, 2247. (h) César, V.; Bellemin-Laponnaz, S.; Gade, L. H. Chem. Soc. Rev. 2004, 33, 619. (i) Scott, N. M.; Nolan, S. P. Eur. J. Inorg. Chem. 2005, 1815. (j) Glorius, F. (Ed.) N-Heterocyclic Carbenes in Transition Metal Catalysis. Topics in Organometallic Chemistry 21, Springer: Berlin, Heidelberg, New York, 2007. (k) Kantchev, E. A. B.; O'Brien, C. J.; Organ, M. G. Angew. Chem., Int. Ed. 2007, 46, 2768.

${ }^{10}$ (a) Nair, V.; Bindu, S.; Sreekumar, V. Angew. Chem., Int. Ed. 2004, 43, 5130. (b) Marion, N.; Díez-González, S.; Nolan, S. P. Angew. Chem., Int. Ed. 2004, 46, 2988. (c) Nolan, S. P. (Ed.) N-Heterocyclic Carbenes in Synthesis; Wiley-VCH: Weinheim, 2006.

${ }^{11}$ Díez-Gonzáles, S.; Nolan, S. P. Coord. Chem. Rev. 2007, 251, 874.

12 (a) Hu, X.; Tang, Y.; Gantzel, P.; Meyer, K. Organometallics 2003, 22, 612. (b) Hu, X.; Castro-Rotrigues, I.; Olsen, K.; Meyer, K. Organometallics 2004, 23, 755. (c) Nemcsok, D.; Wichmann, K.; Frenking, G. Organometallics 2004, 23, 3640. (d) Frenking, G.; Solà, M.; Vyboishchikov, S. F. J. Organomet. Chem. 2005, 690, 6178. (e) Jacobsen, H.; Correa, A.; Costabile, C.; Cavallo, L. J. Organomet. Chem. 2006, 691, 4350. (f) Boehme, C.; Frenking, G. Organomatallics 1998, 17, 5801.

13 (a) Herrmann, W. A.; Schütz, J.; Frey, G. D.; Herdtweck, E. Organometallics, 2006, 25, 2437. (b) Lavallo, V.; Mafhouz, J.; Canac, Y.; Donnadieu, B.; Schoeller, W. W.; Bertrand, G. J. Am. Chem. Soc. 2004, 126, 8670. (c) Doyle, M. J.; Lappert, M. F.; Pye, P. L.; Terreros, P. J. Chem. Soc., Dalton Trans. 1984, 11, 2355. (d) Denk, K.; Sirsch, P.; Herrmann, W. A. J. Organomet. Chem. 2002, 649, 219. (e) Bazinet, P.; Yap, G. P. A.; Richeson, D. S. J. Am. Chem. Soc. 2003, 125, 13314. (f) Khramov, D. M.; Lynch, V. M.; Bielawski, C. W. Organometallics 2007, in press.

14 (a) Mercs, L.; Labat, G.; Neels, A.; Ehlers, A.; Albrecht, M. Organometallics 2006, 25, 5648. (b) Richel, A.; Demonceau, A.; Noels, A. F. Tetrahedron Lett. 2006, 47, 2077. (c) Delaude, L.; Delfosse, S.; Richel, A.; Demonceau, A.; Noels, A. F. Chem. Commun. 2003, 1526. (d) Süßner, M.; Plenio, H. Chem. Commun. 2005, 5417. (e) Süßner, M.; Plenio, H. Angew. Chem., Int. Ed. 2005, 44, 6885. (f) Leuthäußßer, S.; Schwarz, D.; Plenio, H. Chem. Eur. J. 2007, 13, 7195.

15 (a) Alder, R. W.; Allen, P. R.; Williams, S. J. J. Chem. Soc., Chem. Commun. 1995, 1267. (b) Kim, Y.-J.; Streitwieser, A. J. Am. Chem. Soc. 2002, 124, 5757.

${ }^{16}$ Dapprich, S.; Frenking, G. J. Phys. Chem. 1995, 99, 9352.

17 (a) Morokuma, K. J. Chem. Phys. 1971, 55, 1236. (b) Kitaura, K.; Morokuma, K. Int. J. Quantum. Chem. 1976, 10, 325. (c) Ziegler, T.; Rauk, A. Theoret. Chim. Acta 1977, 46, 1. 
${ }^{18}$ For some recent examples, see: (a) Chun-Liang, L.; Wen-Hsin, G.; Ming-Tsung, L.; Ching-Han., H. J. Organomet. Chem. 2005, 690, 5867. (b) Tafipolsky, M.; Scherer, W.; Öfele, K.; Artus, G.; Pedersen, B.; Herrmann, W. A.; McGrady, G. S. J. Am. Chem. Soc. 2002, 124, 5865. (c) Lord, R. L.; Wang, H.; Vieweger, M.; Baik, M.-H. J. Organomet. Chem. 2006, 691, 5505.

19 Theoretical calculations have been reported for phosphorus-based four-membered carbene: Su, M.-D.; Chu, S.-Y. Chem. Phys. Lett. 1999, 308, 283.

${ }^{20}$ (a) Müller, J.; Öfele, K.; Krebs, G. J. Organomet. Chem. 1974, 82, 383. (b) Öfele, K.; Kreiter, C. G. Chem. Ber. 1972, 105, 529 .

${ }^{21}$ (a) Schleyer, P. v. R.; Maerker, C.; Dransfeld, A.; Jiao, H.; van Eikema Hommes, N. J. R. J. Am. Chem. Soc. 1996, 118, 6317. (b) Chen, Z.; Wannere, C. S.; Corminboef, C.; Puchta, R.; Schleyer, P. v. R. Chem. Rev. 2005, 105, 3842. (c) Fallah-Bagher-Shaidaei, H.; Wannere, C. S.; Corminboeuf, C.; Puchta, R.; Schleyer, P. v. R. Org. Lett. $2006,8,863$.

22 (a) Perdew, J. P.; Burke, K.; Ernzerhof, M. Phys. Rev. Lett. 1996, 77, 3865. (b) Perdew, J. P.; Burke, K.; Ernzerhof, M. Phys. Rev. Lett. 1997, 78, 1396. (c) Perdew, J. P.; Ernzerhof, M.; Burke, K. J. Chem. Phys. 1996, 105, 9982. (d) Ernzerhof, M.; Scuseria, G. E. J. Chem. Phys. 1999, 110, 5029.

${ }^{23}$ The TZVP basis sets were used as they are referenced in the Turbomole 5.9 internal basis set library. See ftp://ftp.chemie.uni-karlsruhe.de/pub/ for explicit basis set listings.

${ }^{24}$ Bergner, A.; Dolg, M.; Kuechle, W.; Stoll, H.; Preuss, H. Mol. Phys. 1993, 80, 1431.

${ }^{25}$ Frisch, M. J. et al. Gaussian 03, (Revision D.02), Gaussian, Inc., Pittsburgh, PA, 2003.

26 (a) Laaksonen, L. J. Mol. Graph. 1992, 10, 33. (b) Bergman, D. L.; Laaksonen, L.; Laaksonen, A. J. Mol. Graph. Model. 1997, 15, 301.

${ }^{27}$ Noury, S.; Krokidis, X.; Fuster, F.; Silvi, B. TopMoD, Universite Pierre et Marie Curie, Paris, France, 1997.

${ }^{28}$ Dapprich, S.; Frenking, G. CDA 2.1 University of Marburg, 1994.

${ }^{29}$ ADF2006.01b, SCM, Theoretical Chemistry, Vrije Universiteit, Amsterdam, Netherlands, http://www.scm.com.

${ }^{30}$ (a) van Lenthe, E.; Baerends, E. J. J. Comp. Chem. 2003, 24, 1142. (b) Chong, D. P.; Lenthe, E.; van Gisbergen, S. J. A.; Baerends, E. J. J. Comp. Chem. 2004, 25, 1030.

31 (a) van Lenthe, E.; Baerends, E. J.; Snijders, J. G. J. Chem. Phys. 1993, 99, 4597. (b) van Lenthe, E.; Baerends, E. J.; Snijders, J. G. J. Chem. Phys. 1994, 101, 9783. (c) van Lenthe, E.; Ehlers, A. E.; Baerends, E. J. J. Chem. Phys. 1999, 110,8943 .

${ }^{32}$ Frey, G. D.; Öfele, K.; Krist, H. G.; Herdtweck, E.; Herrmann, W. A. Inorg. Chim. Acta 2006, 359, 2622.

${ }^{33}$ Recent calculations of NICS indices for BN heterocycles, in particular borazine and its substituted derivatives, have shown that the values calculated exactly at the ring plane should not be used in the analysis as they contain significant adverse contributions from the $\sigma$-orbital framework. See: (a) Miao, R.; Yang, G.; Zhao, C.; Hong, J.; Zhu, L. J. Mol. Struct. THEOCHEM 2005, 715, 91. (b) Miao, R.; Yang, G.; Zhao, C.; Hong, J.; Zhu, L. J. Mol. Struct. THEOCHEM 2005, 728, 197.

34 (a) Niehues, M.; Kehr, G.; Frohlich, R.; Erker, G.; Z. Naturforsch., B: Chem. Sci. 2003, 58, 1005. (b) Tafipolsky, M.; Scherer, W.: Öfele, K.; Artus, G.; Peder, B.; Herrmann, W. A.; McGrady, G. S.; J. Am. Chem. Soc. 2002, 124, 5865. (c) Kaur, H.; Zinn, F. K.; Stevens, E. P.; Nolan, S. P. Organometallics 2004, 23, 1157. (d) Wang, H. N. J.; Vasam, C. S.; Tsai, T. Y. R.; Chen, S.-M.; Chang, A. H. H.; Lin, I. J. B. Organometallics 2005, 24, 486. (e) Fructos, M. R.; Belderrain, T. R.; de Fermont, P.; Scott, N. M.; Nolan, S. P.; Diaz-Requejo, M. M.; Perez, P. J. Angew. Chem. Int. Ed. 
2005, 44, 5284. (f) Yu, X.-Y.; Patrick, B. O.: James, B. R. Organometallics 2006, 25, 2359. (g) Herrmann , W. A.; Kocher, C.; Goossen, L. J.; Artus, G. R. J. Chem. Eur. J. 1996, 2, 1627.

${ }^{35}$ See, for example: Wilson, S.; Grant, I. P.; Gyorffy, B. L. (Eds.) The Effects of Relativity in Atoms, Molecules and the Solid-State; Plenum: New York and London, 1991.

${ }^{36}$ The bonding in these complexes can be discussed using the Dewar-Chatt-Duncanson model: (a) Dewar, M. J. S. Bull. Soc. Chim. Fr. 1951, 18, C79. (b) Chatt, J.; Duncanson L. A. J. Chem. Soc. 1953, 2929.

${ }^{37}$ It must be stressed, though, that the calculated total bonding energies are not to be mistaken for (the negative of) bond dissociation enthalpies as the two quantities are not the same: the former do not take into account the relaxation and reorganization processes inherent in real bonding schemes. $\Delta E_{\text {tot }}$ is, however, closely related to bond enthalpy terms which provide a good approximation for bond strengths. Hence, the discussion presented herein is indicative at least.

38 (a) Bagus, B. S.; Hermann, K.; Bauschlicher, C. W. Jr. J. Chem. Phys. 1984, 80, 4378. (b) Bagus, P. S.; Illas, F. J. Chem. Phys. 1992, 96, 8962.

${ }^{39}$ See, for example: (a) Frenking, G.; Idun, U. J. Chem. Soc., Dalton Trans. 1997, 1653. (b) Pidun, U.; Frenking, G. J. Organomet. Chem. 1996, 525, 269. (c) Pidun, U.; Frenking, G. Organometallics 1995, 14, 5325. (d) Dapprich, S.; Frenking, G. Organometallics, 1996, 15, 4547.

40 The relative $\sigma$-donating ability of carbenes has been studied in the literature using electron localization function analysis (ELF); see Frison, G.; Sevin, A. J. Phys. Chem. A 1999, 103, 10998. Although the population of the monosynaptic valence basin corresponding to the carbene lone pair has been used to assess the $\sigma$-donor nature of NHCs, our results for 1-6 indicate this approach to be somewhat questionable as the trends in acidity constants and carbene-metal bonding energies observed are, by no means, consistent with those in the basin population. As a matter of fact, carbene 3, which will prove to be an excellent $\sigma$-donor, shows the smallest basin population in the series and, moreover, the second largest value is associated with $\mathbf{5}$, the poorest $\sigma$-donor of $\mathbf{1 - 6}$. These results suggest that the monosynaptic valence basin properties do not generally function as a measure of $\sigma$-donor tendency. This is to be expected as there is no direct physical interpretation for an ELF basin or its population. For description of the ELF isosurfaces, see Supporting Information.

${ }^{41}$ Magil, A. M.; Cavell, K. J.; Yates, B. F. J. Am. Chem. Soc. 2004, 126, 8717.

42 Barone, V.; Cossi, M. J. Phys. Chem. A 1998, 102, 1995. 